\title{
IMMERSION AS A FACTOR IN THE DEVELOPMENT OF HYPERTENSION
}

\author{
BY \\ OLIVER GARAI* \\ From the Sutton Emergency Hospital, Surrey \\ Received August 21, 1945
}

During the course of routine physical examinations of men admitted to an Emergency Medical Service neurosis centre it was noticed that high blood pressure readings were being recorded not infrequently. The impression was formed that the high values were more frequent in men of the Merchant Navy who had been shipwrecked.

It seemed worth while to attempt to confirm the presence or absence of an abnormal degree of vasomotor reaction in such men, especially as some work has already been done to show that there is possibly just such an exaggerated vasomotor reaction in those subjects who are potential candidates for the later development of essential hypertension (Hines and Brown, 1933).

The working hypothesis formed was that, as a result of exposure to cold for abnormally prolonged periods under circumstances increasing heat loss to an unusual extent, there is a reflex vasoconstriction of renal vessels which is prolonged sufficiently to produce damage to the kidney. Moreover, such exposure may bring about changes in the kidney so that in future it is hypersensitive to cold stimuli applied externally, or that the cycle of events leading to production of pressor substances may be initiated. It was planned originally that in each case investigated an estimate of renal function would be made, but this proved to be impossible owing partly to the shortage of laboratory staff, the pressure of routine work, and the shortage of nursing staff. Only ward testing of the urine for albumen was carried out on admission. No abnormalities were found in any case.

A group of 15 physically fit men of the Merchant Navy, all of whom had been immersed, were taken, in succession, on their admission and were used for the investigation.

To act as controls a group of non-immersed neurotic men and a group of non-immersed non-neurotic men were also tested in the same manner.

The test used was practically identical with that described by Hines and Brown (1940) and will be detailed below.

\section{The Cold Pressor Test}

The tests were all carried out in a quiet room with which the men were familiar and in which they had been lying recumbent on a couch for one hour. To allay anxiety the nature of the test had previously been explained. With the subjects recumbent and comfortably relaxed, a series of blood pressure readings were taken at two-minute intervals until a steady basal level for three consecutive readings was obtained. A bowl of water and ice at a steady $4^{\circ} \mathrm{C}$. was so arranged as to enable the free hand to be immersed up to the wrist without the necessity of any movement on the part of the subject. Immersion was maintained for two minutes while readings of blood pressure were taken at half-minute intervals. The hand was then withdrawn and dried while blood pressure readings were taken at half-minute intervals until the levels returned to the pre-immersion figures. A physical examination to exclude organic disease was also carried out. Special attention was paid to the past

\footnotetext{
* With a statistical note by Eliot Slater.
} 
history of scarlet fever, nephritis, pyelitis, hypertension, rheumatic fever, or a family history suggestive of hypertension such as strokes or sudden death.

The normal response to the test of men within the ages of 20 to 40 is a systolic rise not exceeding $20 \mathrm{~mm}$. and a diastolic rise not above $15 \mathrm{~mm}$. returning to normal within 2 minutes (Hines and Brown, 1940). These observers state that as a result of analysis of a large number of tests an elevation above the basal level of more than $20 \mathrm{~mm}$. systolic pressure and more than $15 \mathrm{~mm}$. diastolic pressure indicates a hyper-reactive type of response to the stimulus. They quote a total of 1842 subjects with normal blood pressures and 1117 with essential hypertension in whom the results obtained show that the mean response in cases with essential hypertension is from 2 to 6 times greater than those obtained from the subjects with a normal blood pressure. Writing six years after their original investigations of 66 subjects with normal blood pressure they had traced all but three of their 24 originally " normal hyperreactors ": 38 per cent of these were found to have developed essential hypertension, but of the 28 traced out of 42 originally " normal hypo-reactors" none had developed hypertension.

The rise in blood pressure following immersion of the hand in water at $4^{\circ} \mathrm{C}$. is a reflex response, the afferent arc of which is apparently those fibres in peripheral nerves that convey sensations of pain and temperature. This is suggested by the results obtained in a patient with syringomyelia, aged 27 , with anæsthesia to pain and temperature over the right arm. The results of the cold pressor test carried out on this man were as follows.

Right arm. 108/70; 108/64; 108/64. Immersion. $110 / 66, \frac{1}{2}$ minute; $110 / 64,1$ minute; 108/64, 2 minutes.

Maximum rise $\mathrm{S} / \mathrm{D}=2 / 2$.

Left arm. 120/58;120/58; 120/58. Immersion. 125/85, $\frac{1}{2}$ minute; 155/90, 1 minute; 150/80, 2 minutes; 130/70, 3 minutes.

Maximum rise $\mathrm{S} / \mathrm{D}=35 / 32$.

A similar finding was reported by Sullivan (Sullivan, 1941) in a case with complete transection of the spinal cord in the lumbar region. He found a normal response in the arms, but a response of only $10 / 0$ in the legs.

\section{Results OBTAINED}

All cases were men of the Merchant Navy who had been shipwrecked, usually following torpedoeing or the striking of a mine. Of the 15 in this group, 14 had been shipwrecked within 5 to 15 months of the test. One man, case 41 , had been shipwrecked 29 months previously and he gave a response to the test of $S / D=5 / 5$ returning to normal in 3 minutes, i.e. within normal limits, except as regards time which was prolonged by one minute. This man had been torpedoed off Iceland in 1941 and was in the water for five days hanging from the keel of an overturned lifeboat: he later had immersion foot. Case 20 was on a ship which was torpedoed in the North Atlantic in August 1942 and was in an open boat for 35 days; it was the rainy season and he was wet all the time. This man gave a result of $\mathrm{S} / \mathrm{D}=72 / 44$ taking 6 minutes to return to normal: on admission his blood pressure was 130/85. Case 11 was shipwrecked on two occasions in the South Atlantic each time. On the first occasion in 1942 he was immersed for 2 hours, the second for 34 hours. His blood pressure on admission was $185 / 130$, and six weeks later was still $165 / 110$, but he gave a basal blood pressure of $130 / 80$ after 60 minutes rest before the cold pressor test was carried out. His response to the test was $S / D=50 / 40$ returning to basal levels in 5 minutes.

The above histories are typical of the more severely exposed men. In the whole group the least degrees of exposure to cold and wet were suffered by Cases 10 and 33 .

In Case 10, who was immersed for not more than 2 hours, a response of $S / D=40 / 30$ was obtained, returning to normal in 8 minutes. Case 33 got straight into an open boat 500 miles off the coast of South America in midsummer. It was dry for five days and rained continually for two days, this constituting the only exposure to water. His response was $S / D=16 / 28$, returning to normal in 4 minutes.

The other 10 men received degrees of exposure varying considerably, but falling between the extremes of those related above.

The only 2 men out of the 15 in this group with family histories at all suggestive of hyper- 
tension were Cases 29 and 41. In Case 29 the man's mother, aged 78, had had a stroke, and his father had died of heart failure; this sailor gave a response of $S / D=12 / 26$, returning to normal in 4 minutes. Case 41, whose father had had strokes and later died at the age of 68, gave a result $S / D=5 / 5$, returning to normal in 3 minutes, but as noted above this man was exceptional in that 29 months had elapsed between shipwreck and cold pressor test.

It is to be noted that 3 of these 15 men gave test results within the range of the normal as defined by Hines and Brown (1940). Of these, Case 18 had been shipwrecked twice: on the first occasion, 3 years before the test, he was in an open boat in the Arctic circle for 12 hours; the second time was 9 months prior to testing and he was in a water-filled open boat in midAtlantic-wearing only a singlet-for 10 hours. Case 31 had been torpedoed 8 months previously between Freetown and Takeradi, he was in the sea 6 hours and then in an open boat for 9 hours and said it was cold. Case 41 has already been described as one of the examples of severe exposure.

Control Group 1 (Non-immersed Neurotic). This group consisted of 9 patients with the diagnosis of anxiety state, in whom there was no evidence of any organic disease, neither had any of them ever been shipwrecked. In this group Case 25 gave a result outside normality, but he gave a past history of frequent attacks of tonsillitis. Case 27 gave an abnormal diastolic response to the test and also took 4 minutes to return to normal. Case 45 gave an abnormal diastolic response and took 3 minutes to return to normal, but here it is interesting to note that a past history of scarlet fever and nephritis were obtained and he now suffers from backache and has frequency of micturition.

Control Group 2 (Non-immersed Non-Neurotic). Eleven men constitute this group: all were patients in a general medical ward who were awaiting discharge home having recovered from such ailments as fibrositis, minor upper respiratory infections, and peptic ulcer. No member of this group had been shipwrecked and all were passed as normal from the psychiatric point of view. Case 51 gave an S/D rise of $13 / 25$, returning to normal in 3 minutes. This man had spent 3 years in a Prisoner of War camp in Poland where the tëmperature was often $30^{\circ}-40^{\circ} \mathrm{F}$. below freezing. Case 38 with an S/D rise of $22 / 20$ and a return to normal in 3 minutes was anxious and would not relax during the test; his disability was fibrositis of the back. Case 36 with an S/D rise of 18/19 returning to normal in 3 minutes, swims a great deal and took part in seaborne invasion, necessitating wading for some time and the usual pre-invasion exercises. Case 50, with a dislocated ankle, had never been immersed; he was 24 years old and gave the abnormal S/D rise of 29/32 taking 4 minutes to return to normal. Case 49 also gave a family history that his father had died at 65 years having had three strokes and his paternal aunt also died following a stroke; his S/D rise was $18 / 16$ and took 4 minutes to return to normal. It is worth noting that case 47 with an S/D rise of $4 / 9$ returning to normal in 2 minutes is a non-swimmer.

\section{Statistical Results by Eliot Slater}

The results of the tests are given in Table I, and their statistical analysis in Table II. No correlation was found between the test results and the bodily habitus - asthenic, athletic, or pyknic - or between test results and psychiatric diagnosis-anxiety state, hysteria, depression, etc. We may note from Table I that there are small differences between the three groups in respect of age and systolic and diastolic blood pressure, but that much bigger differences are found in the test results. The immersed men gave a mean systolic rise of $25 \mathrm{~mm}$., a mean diastolic rise of $23 \mathrm{~mm}$., and the rise of blood pressure was maintained for a mean time of 5 minutes. In the other two groups the corresponding figures are: (non-immersed neurotic) 13 and $15 \mathrm{~mm}$. for 3.4 minutes and (non-immersed non-neurotics) 14 and $15 \mathrm{~mm}$. for $3 \cdot 1$ minutes.

The ages of these men and their basal systolic and diastolic blood pressures, which are also recorded, do not show any significant differences between the three clinical groups. Furthermore, they do not show any significant association with the factors analysed above. They can therefore be neglected for the purpose of discriminating the immersed men from the others. 
Table I.-Results of the Tests

\begin{tabular}{|c|c|c|c|c|c|c|c|}
\hline No. & Age & $\begin{array}{l}\text { Systolic } \\
\text { pressure }\end{array}$ & $\begin{array}{l}\text { Diastolíc } \\
\text { pressure }\end{array}$ & $\begin{array}{l}\text { Systolic } \\
\text { rise }\end{array}$ & $\begin{array}{l}\text { Diastolic } \\
\text { rise }\end{array}$ & $\begin{array}{l}\text { Time required to } \\
\text { return to normal } \\
\text { as } \frac{1}{2} \text { minutes }\end{array}$ & $\begin{array}{c}\text { Discriminant } \\
\text { function calculated } \\
\text { from S.R., D.R. } \\
\text { and T. }\end{array}$ \\
\hline \multicolumn{8}{|c|}{ Immersed } \\
\hline $\begin{array}{r}6 \\
10 \\
11 \\
16 \\
18 \\
19 \\
20 \\
22 \\
26 \\
29 \\
30 \\
31 \\
32 \\
33 \\
41 \\
\text { Mean }\end{array}$ & $\begin{array}{l}23 \\
36 \\
23 \\
22 \\
36 \\
41 \\
23 \\
40 \\
24 \\
35 \\
30 \\
36 \\
21 \\
23 \\
26 \\
29 \cdot 2\end{array}$ & $\begin{array}{l}150 \\
125 \\
130 \\
114 \\
120 \\
104 \\
108 \\
132 \\
126 \\
118 \\
135 \\
125 \\
108 \\
126 \\
145 \\
124 \cdot 4\end{array}$ & $\begin{array}{l}75 \\
68 \\
80 \\
50 \\
64 \\
72 \\
76 \\
90 \\
65 \\
64 \\
75 \\
72 \\
62 \\
72 \\
75 \\
70 \cdot 7\end{array}$ & $\begin{array}{l}20 \\
40 \\
50 \\
11 \\
15 \\
41 \\
72 \\
23 \\
14 \\
12 \\
20 \\
10 \\
22 \\
16 \\
5 \\
24 \cdot 7\end{array}$ & $\begin{array}{c}25 \\
36 \\
45 \\
20 \\
6 \\
22 \\
44 \\
15 \\
25 \\
26 \\
21 \\
10 \\
18 \\
28 \\
5 \\
23 \cdot 1\end{array}$ & $\begin{array}{c}12 \\
16 \\
10 \\
14 \\
10 \\
10 \\
12 \\
8 \\
8 \\
8 \\
10 \\
6 \\
10 \\
10 \\
6 \\
10 \cdot 0\end{array}$ & $\begin{array}{l}5 \cdot 0 \\
6 \cdot 7 \\
4 \cdot 0 \\
5 \cdot 9 \\
4 \cdot 4 \\
4 \cdot 3 \\
5 \cdot 0 \\
3 \cdot 4 \\
3 \cdot 2 \\
3 \cdot 2 \\
4 \cdot 2 \\
2 \cdot 5 \\
4 \cdot 3 \\
4 \cdot 1 \\
2 \cdot 6 \\
4 \cdot 19\end{array}$ \\
\hline \multicolumn{8}{|c|}{ Non-immersed neurotic } \\
\hline $\begin{array}{r}7 \\
9 \\
23 \\
25 \\
27 \\
43 \\
44 \\
45 \\
46 \\
\text { Mean }\end{array}$ & $\begin{array}{l}23 \\
24 \\
24 \\
36 \\
21 \\
37 \\
25 \\
24 \\
21 \\
26 \cdot 1\end{array}$ & $\begin{array}{l}125 \\
130 \\
122 \\
118 \\
120 \\
120 \\
128 \\
112 \\
120 \\
121 \cdot 7\end{array}$ & $\begin{array}{l}75 \\
60 \\
58 \\
75 \\
76 \\
78 \\
70 \\
65 \\
80 \\
70 \cdot 8\end{array}$ & $\begin{array}{l}10 \\
10 \\
3 \\
22 \\
20 \\
10 \\
12 \\
18 \\
15 \\
13 \cdot 3\end{array}$ & $\begin{array}{r}13 \\
8 \\
12 \\
15 \\
29 \\
8 \\
12 \\
25 \\
15 \\
15 \cdot 2\end{array}$ & $\begin{array}{l}6 \\
6 \\
5 \\
8 \\
8 \\
6 \\
6 \\
6 \\
9 \\
6 \cdot 7\end{array}$ & $\begin{array}{l}2 \cdot 5 \\
2 \cdot 6 \\
2 \cdot 0 \\
3 \cdot 4 \\
3 \cdot 2 \\
2 \cdot 6 \\
2 \cdot 5 \\
2 \cdot 4 \\
3 \cdot 8 \\
2 \cdot 78\end{array}$ \\
\hline \multicolumn{8}{|c|}{ Non-immersed non-neurotic } \\
\hline $\begin{array}{c}35 \\
36 \\
37 \\
38 \\
39 \\
40 \\
47 \\
48 \\
49 \\
50 \\
51 \\
\text { Mean }\end{array}$ & $\begin{array}{l}26 \\
39 \\
24 \\
37 \\
44 \\
22 \\
21 \\
25 \\
39 \\
24 \\
24 \\
29 \cdot 5\end{array}$ & $\begin{array}{l}105 \\
120 \\
122 \\
138 \\
120 \\
132 \\
130 \\
116 \\
110 \\
105 \\
115 \\
119 \cdot 4\end{array}$ & $\begin{array}{l}60 \\
76 \\
64 \\
85 \\
75 \\
94 \\
76 \\
65 \\
68 \\
64 \\
70 \\
72 \cdot 5\end{array}$ & $\begin{array}{r}15 \\
18 \\
8 \\
22 \\
4 \\
8 \\
4 \\
16 \\
18 \\
29 \\
13 \\
14 \cdot 1\end{array}$ & $\begin{array}{c}10 \\
19 \\
11 \\
20 \\
0 \\
16 \\
9 \\
9 \\
16 \\
32 \\
25 \\
15 \cdot 2\end{array}$ & $\begin{array}{l}6 \\
8 \\
5 \\
6 \\
4 \\
6 \\
5 \\
6 \\
8 \\
8 \\
6 \\
6 \cdot 2\end{array}$ & $\begin{array}{l}2 \cdot 6 \\
3 \cdot 3 \\
2 \cdot 1 \\
2 \cdot 5 \\
1 \cdot 8 \\
2 \cdot 4 \\
2 \cdot 1 \\
2 \cdot 6 \\
3 \cdot 4 \\
3 \cdot 2 \\
2 \cdot 3 \\
2 \cdot 57\end{array}$ \\
\hline
\end{tabular}

Table II.-Statistical Analysis of Results

\begin{tabular}{|c|c|c|c|c|c|}
\hline & $\begin{array}{l}\text { Degrees } \\
\text { of } \\
\text { freedom }\end{array}$ & $\begin{array}{l}\text { Systolic rise } \\
\text { in blood } \\
\text { pressure }\end{array}$ & $\begin{array}{l}\text { Diastolic rise } \\
\text { in blood } \\
\text { pressure }\end{array}$ & $\begin{array}{l}\text { Time taken to } \\
\text { return to the } \\
\text { basal blood } \\
\text { pressure }\end{array}$ & $\begin{array}{l}\text { Discriminant } \\
\text { function }\end{array}$ \\
\hline $\begin{array}{l}\text { Total variance } \ldots \\
\text { Percentage attributable to: } \\
\text { (a) Difference between im- } \\
\text { mersed and non-immersed }\end{array}$ & 34 & $6590 \cdot 68$ & $3736 \cdot 57$ & $247 \cdot 88$ & $43 \cdot 36$ \\
\hline $\begin{array}{l}\text { men } \text { (b) Difference between } \\
\text { sub-classes of non-immersed }\end{array}$ & 1 & $15 \cdot 69$ & $14 \cdot 20$ & $44 \cdot 81$ & $46 \cdot 16$ \\
\hline$\underset{(c)}{\operatorname{men}}$ Variance within groups & 1 & 0.04 & 0.00 & 0.47 & 0.49 \\
\hline $\begin{array}{l}\text { (error) } \\
(d) \text { Variance ratio (a/d.f. : }\end{array}$ & 32 & $84 \cdot 27$ & $85 \cdot 80$ & $54 \cdot 72$ & $53 \cdot 35$ \\
\hline $\begin{array}{ccc}\text { c/d.f.) } & \\
\text { Probability less than } & \ldots & \ldots\end{array}$ & 二 & $\begin{array}{l}5.96 \\
0.05\end{array}$ & $\begin{array}{l}5 \cdot 28 \\
0.05\end{array}$ & $\begin{array}{c}26 \cdot 21 \\
0 \cdot 001\end{array}$ & $\begin{array}{c}27 \cdot 68 \\
0.001\end{array}$ \\
\hline
\end{tabular}


Systolic rise, diastolic rise, and time are all closely related variables. They form different aspects from which the function that differentiates immersed from non-immersed men can be viewed. Using all three variables together to measure their discriminant function as accurately as possible, the correct proportions in which each should be weighted are S.R. +0.0058 , D.R. -0.0147 , T. +0.4390 (for procedure used see Mather, Statistical Analysis in Biology, p. 152, London, 1943). The variable X shown above is the weighted sum of the three measurements for each man. When analysed, as shown, it is found not to discriminate significantly between immersed and non-immersed men better than $T$ alone. Therefore, although systolic and diastolic rises are relevant information for discriminating between the two groups, they can be neglected when time has been recorded.

Since non-immersed neurotic men do not differ from non-immersed non-neurotic men in respect of systolic rise, diastolic rise, time taken to return to basal blood pressure, or the weighted combination of all three, it is reasonable to infer that these characteristics differentiate immersed men from normal men as a consequence of immersion and not as a consequence of neurosis.

\section{Discussion}

We conclude, therefore, that there is a significant difference in the test results between the men who had been exposed to wet and cold and those who had not. This tends to support the hypothesis, from which we started, that such exposure if severe and prolonged can be expected to have a damaging effect on the normal kidney.

That there is an association between exposure to cold and/or wet and alteration in renal function is well substantiated. As early as 1873 Johnson in a paper read before the Clinical Society of London described how a medical student of 22 years, previously healthy, developed albuminuria, fatigue, and headache after a cold bathe of only fifteen minutes. The albuminuria on this occasion lasted only twenty-four hours. One week later a further cold bathe caused a repetition of the symptoms, but on this occasion the albuminuria persisted for nineteen days. Two further cases of albuminuria after bathing were described by Johnson where it was known that none existed before. Unfortunately at that time estimation of blood pressure was not easily carried out, neither were casts looked for in the urine.

Mudd and Grant (1919) showed that on chilling the skin of the back there followed a marked depression of the temperature of the pharyngeal mucous membrane in normal subjects, the fall being due to vasoconstriction and not to a fall in blood pressure or blood temperature, both of which in fact rose slightly. They found that whereas the skin readily regained its pre-cooling state as regards temperature the mucosa on the other hand showed a prolonged fall of temperature and did not regain its normal temperature in twelve minutes. This may indicate a prolonged vasoconstriction of the mucosal vessels in the pharynx. This observation of Mudd and Grant serves to indicate that the vasoconstrictor changes are not confined to the skin after exposure to cold. The albuminuria noticed by Johnson after bathing may likewise indicate a functional connection as regards response to cold or pain between the skin and renal vessels.

As regards the intensity of the stimulus that results from immersion in cold water, it must be noted that the cooling effect of water is fourteen times as great as that of air. Thus a cold bath at $4 \cdot 4^{\circ} \mathrm{C}$. causes the heat production of the body to increase twelve-fold in the first ten minutes. After this the heat production mechanism becomes depressed and the body temperature begins to fall (Best and Taylor).

The actual stimulus causing these changes is not the perception of the degree of coldness, but the pain associated with the lower ranges of temperature when perceived for a longer period. This mechanism of the response of the blood pressure to cold is borne out by the observations of Pickering and Kissin (1936), who thought in the small series of patients examined by them that the size of the response seemed to be related to the degree of discomfort that the subject experiences, and was to a large extent independent of the resting blood pressure. In their investigation immersion was carried out for the slightly longer period of three minutes.

Wolf and Hardy (1943) concluded that the cold pressor effect is a measure of reaction to 
pain and that such pain is altogether separate from the sensation of cold itself. The pain is probably mediated through small non-myelinated fibres of class $C$. In the case of syringomyelia described in the first part of this paper no significant rise in blood pressure was obtained on immersing a hand devoid of pain and temperature sense, whereas the other hand with intact sensation consistently gave a hyper-reactive response. It would be interesting to know what the response in cases of hysterical anæsthesia would be.

Experimentally Ariel et al. (1943) found that rabbits exposed to a temperature of $3^{\circ} \mathrm{C}$. for periods up to 48 hours secreted no urine during this time though the animals were incontinent of fæces (presumably the normal habit in rabbits). This may suggest a profound degree of renal vaso-constriction as a result of cold in the rabbits, together with a fall in metabolic rate generally.

Wertheimer (1894) showed experimentally that cooling of the skin caused a contraction of the renal vessels.

It is interesting to note that other factors are probably concerned in producing persistent hypertension. Thus Graham (1945) showed in a representative sample of all ranks and services of an armoured brigade of considerable experience in Western Desert campaigning that in 695 men a mean blood pressure of $154 / 90$ was found. Of these 695,27 per cent had diastolic pressures over $100 \mathrm{~mm}$., and 38 per cent had systolic pressures over $160 \mathrm{~mm}$. Two months later 28 of this 27 per cent. had returned nearly to normal as regards blood pressure. Graham is of the opinion that prolonged and repeated battle strain with its hyper-adrenalinæmia, as shown by the fast pulse, pale face, and enlarged pupils, is the chief factor responsible. In a catastrophe such as shipwreck any hyper-adrenalinæmia produced as a result of emotional reaction would serve to accentuate further the response to the cold immersion itself.

Observations by Homer Smith (1939) are also indicative of variations occurring in renal blood flow as a result of emotion. During the estimation of renal blood flow by means of diodrast clearance, inulin clearance, cardiac output, and urine flow, Smith noticed in one subject that during the third estimation " a rumour of a disturbing nature . . . reached the subject . . . the only objective signs of autonomic disturbance were marked sweating of the face and hands, but the renal blood flow was abruptly decreased by 40 per cent. Another subject during the tests misinterpreted their significance and "became increasingly restless, alarmed, and remonstrative"; during the peak of this phase the degree of renal vasoconstriction that occurred "was as profound as any we have seen after the administration of large doses of adrenalin." No mention, however, is made as to the presence or absence of albuminuria during these episodes.

The foregoing results may be interpreted as showing that following prolonged immersion in cold water an alteration in response to the test used is found between the immersed and non-immersed groups. It is conceivable that cold causes a reflex contraction of afferent or efferent arterioles of such a degree that the delicate glomerular apparatus becomes damaged and thus rendered permeable to albumen which is then excreted in the urine. At the same time the ischæmic kidney as a self-protective mechanism causes a rise in systemic blood pressure by means of its pressor substances, as an ischæmic kidney is well known to do. If the period of renal ischæmia is short then the glomerular damage may be slight and non-progressive or reversible, but if of longer duration, probably of some hours, then the changes induced may no longer be reversible and the renal tissue may become hypersensitive to further short periods of ischæmia induced by short periods of exposure, or to exposure to temperatures which would previously have been ineffectual in bringing about the response. In this way a vicious cycle may be set up which leads to the development of established hypertension.

\section{SUMMARY}

Men of the Merchant Navy, who had been shipwrecked, were noticed on admission to hospital to show a high incidence of raised blood pressure. The response of such shipwrecked men to a standard " cold pressor test" is shown to be different from that of two control groups. The results are analysed statistically and there is seen to be a significant 
difference between the three groups: analysis shows this difference to be associated with the factor of immersion. The possible significance of this difference is discussed in its relation to hypertension.

I wish to express my appreciation to Dr. Denis Hill for much helpful criticism during the investigations and also to Dr. Terence East for helpful suggestions and criticisms.

The investigations were carried out at Sutton Emergency Hospital, Sutton, Surrey.

\section{REFERENCES}

Ariel, I., Bishop, F. W., and Warren, S. L. (1943). Cancer Research, 3, 449.

Best, C. H., and Taylor, N. B. Physiological Basis of Medical Practice, 3rd. edit., p. 1055.

Graham, J. A. P. (1945). Lancet, 1, 239.

Hines, E. H. (1940). Amer. Heart J., 19, 408.

$\longrightarrow$, and Brown, G. E. (1933). Annals intern. Med., 7, 209.

Smith, H. W. (1939-40). Harvey Lecturer Series 35, 205.

Johnson, G. (1873). Brit. med. J., 2, 664.

Mudd, S., and Grant, S. B. (1919). J. med. Research, 10, 53.

Pickering, G. W., and Kissin, M. (1936). Clin. Sci., 2, 201.

Sullivan, J. A. (1941). J. Amer. med. Ass., 117, 1090.

Wertheimer, E. (1894). Arch. physiol. normal path. (series 5), 6, 308.

Wolf, S., and Hardy, J. A. (1943). Research publication of the Association for Research in Nervous and Mental Disease. Vol. 111, Pain, 123-141. 